\title{
Decision Method of Layout of Time-Sharing Leasing Automobile Network
}

\author{
Qiliang Ren, Lili Zhang* and Ziyu Zhao \\ School of Traffic and Transportation, Chongqing Jiaotong University, Chongqing 400074, China
}

\begin{abstract}
In order to improve the rationality of network layout of time-sharing leasing car, this paper studies the method of network layout of time-sharing leasing car combined with two target shortest path optimization model. Firstly, selecting the address suitable for the construction of time-sharing leasing car network according to the condition; Secondly, building the two target optimization model with the objective of minimum travel time and minimum construction cost, this model considers fully multiple transfer modes which from the starting point to the leasing point or the returning point to the destination, including walking, shared bicycle transit, public transportation transit, rail transit, taxi transit and so on, and calculate the travel time weight of different ways; Thirdly, introducing the travel times of the starting point, the sharing rate of time-sharing leasing car and different transfer modes, calibrating the weight of each path; Lastly, designing the solution method of the model according to the basic algorithm of Dijkstra, and verify the practicability of the model by an example. The results show that the proposed method of network layout of time-sharing leasing car can be effectively applied to the network layout planning of current time-sharing leasing car, it plays an active role in saving the travel time of passengers and reducing the cost of construction. This study provides a more practical and reasonable method for the network layout planning of timesharing leasing car.
\end{abstract}

Keywords-transportation planning; network layout; double-objective path model; time-sharing leasing automobile; travel time; construction cost

\section{INTRODUCTION}

With the rapid development of China's economy and society and the increasing frequency of people's travel, people's demand for motorized travel is growing. The high cost of purchasing cars, high travel costs, the waste of resources caused by long-term parking, and the adoption of vehicle purchase restriction and traffic restriction measures in some big cities have brought a lot of inconvenience to private car travel. Therefore, in the environment of shared economic development, time-sharing leasing automobile emerges as the times require [1,2] time-sharing leasing automobile is convenient and flexible. On the one hand, it can meet the short-term and short-distance travel needs of local residents or resident population. On the other hand, it can meet the individual travel needs of temporary immigrants such as tourism and official business. For travelers, it not only reduces travel costs, but also improves travel efficiency [3]. For social development, the use of private cars has been effectively reduced, which has made great contributions to alleviate traffic congestion and reduce traffic pollution to the environment [4].

Time-sharing leasing has attracted wide attention of scholars at home and abroad. Correia \& Autunes [5] studied the layout and scale of car rental stations, and proposed a linear programming model with the operator's total profit as the objective function; Cepolina \& Farina [6] takes the single lease of electric vehicles as the research object, and analyses the rationality of its scale and vehicle configuration. Li Ming [7] discussed the development advantages, obstacles and effective measures of electric vehicle time-sharing lease; Changling Zhang [8] makes a detailed analysis of the time-sharing leasing model of electric vehicles and puts forward some improvement methods. It can be seen that the existing research has made outstanding contributions to the improvement of the development of time-sharing leasing automobile, but the research on the layout planning of time-sharing lease automobile network can not fully meet the needs of timesharing leasing automobile network layout. In order to further improve the development system of time-sharing leasing automobile, it is necessary to study the layout method of time-sharing leasing automobile network.

The layout of time-sharing leasing automobile network is influenced by many factors, such as land use nature, travel time, construction cost, etc. This paper will fully consider the convenience of travel and the optimization of construction cost of time-sharing leasing automobile network, and construct the optimal location model of timesharing leasing automobile network, so as to improve the scientificity and rationality of time-sharing leasing automobile network layout.

\section{COnStruction OF Time-Sharing Rental Vehicle NETWORK LAYOUT MODEL}

\section{A. Model Hypothesis}

Firstly, the influence scope of automobile rental network should be determined. If the maximum service radius of automobile rental network is $R$ and the maximum service area is $\pi R^{2}$, the service area of automobile rental network should satisfy $S \leq \pi R^{2}$, and the centroid of service area is clear. Secondly, determine the requirements of car rental 
network within the scope of service. The number of car rental demand is $H$ within the scope of $S$. The critical number of car rental demand for building a car rental network is $h$. When the number of car rental network demand is greater than $h$, the rental network needs to be built. Assuming that the number of car rental network within the scope of service meets $H \geq h$, it is necessary to set up car rental point within this scope. Thirdly, the initial choice of car rental outlets. There are two or more locations within the scope of service that can be used to build rental network, expressed in $x_{2}, \cdots, x_{n}$, and each of the alternative network areas is large enough to meet the parking requirements of rental cars. Finally, for the convenience of the study, government agencies, transportation hubs, large-scale hotels, commercial centers, tourist attractions and residential areas are taken as the starting points (as well as destinations) of people's concentration. It is assumed that $n$ starting points can be obtained within the scope of the study, and the starting point of each nature of land use rental car travel sharing rate can be known, the number of car demand for each starting point can be calculated.

\section{B. Double-objective Shortest Path Model Construction}

The layout of car rental outlets should fully consider the convenience of people's travel and the lowest construction cost to ensure the quality of the shortest route for passengers and investors. Therefore, in this paper, the shortest path model is used to select the shortest path weights which represent people's travel time and construction cost. The location with the shortest travel time and the lowest construction cost is calculated as the best leasing point $[9,10]$.

Set $G=(P, Q, E)$ as a non-empty simple map, where $P$ is the starting point or destination, $P_{1}$ is the starting point and $P_{2}$ is the destination; $Q$ is the alternative for car rental network, and the best rental network will be selected from the alternative network. It can be expressed as: $Q=\left\{Q_{l}\right.$, $\left.Q_{2}, \cdots, Q_{m}\right\} ; E$ is a set of travel paths, each side will have a non-negative real weight, which can be expressed by travel time and construction cost, and can be expressed. Set $z_{1}(i, j)$ and $z_{2}(i, j)$ as the travel time weight of the path and the cost weight of the path, to get a two-objective selection model [11], define $y_{i j}$ as:

$$
\left\{\begin{array}{l}
y_{i j}= \begin{cases}1 & \text { There are directed edges } \\
\text { between node } i \text { and node } j \\
\text { otherwise }\end{cases} \\
\sum_{j} y_{i j} \leq 1 \quad \forall i \in e \\
\sum y_{i j} \in\{0,1\} \quad \forall(i, j) \in P, Q
\end{array}\right.
$$

Therefore, the two-objective objective shortest path model is set up as follows:

$$
\begin{aligned}
& \left\{\begin{array}{l}
\min z_{1}=\sum_{i j} y_{i j} z_{1}(i, j) \\
\sum_{j} y_{i j} \leq 1 \quad \forall i \in e \\
\sum_{i j} y_{i j} \in\{0,1\} \quad \forall(i, j) \in P, Q
\end{array}\right. \\
& \left\{\begin{array}{l}
\min z_{2}=\sum_{i j} y_{i j} z_{2}(i, j) \\
\sum_{j} y_{i j} \leq 1 \quad \forall i \in e \\
\sum y_{i j} \in\{0,1\} \quad \forall(i, j) \in P, Q
\end{array}\right.
\end{aligned}
$$

In Figure $\mathrm{G}$, the path of the minimum travel time weight min $z_{1}$ and the minimum construction cost weight $z_{2}$ obtained by the optimization algorithm is the shortest path. At this time, the leasing point is the best location for the time-sharing leasing automobile network [12].

Travel time weight $z_{1}$ is the ratio of path distance to travel speed between nodes. The time weights of travelers from starting point to destination include the time consumed by travelers from starting point to leasing point, the time consumed by renting point to return point, and the time consumed by return point to destination. Among them, there are many ways of arriving at the leasing point and the return point to the destination from the starting point. Including pedestrian, shared bicycle, bus, rail transit, taxi and other modes, the speed of different modes of travel varies greatly; The time consumed from the lease point to the return point mainly considers the running time of the vehicle. The construction cost of time-sharing leasing automobile network mainly includes land use price, construction cost and maintenance cost. Therefore, the equations for calculating the weights of travel time and construction cost are as follows:

$$
\left\{\begin{array}{l}
z_{1}=\sum_{m} \frac{l_{m}}{v_{m}}+\frac{l_{2}}{v_{2}}+\sum_{n} \frac{l_{n}}{v_{n}} \\
z_{2}=\sum_{r=1}^{2} \sum_{k=1}^{K} y_{r k}
\end{array}\right.
$$

In the (4), $l_{m}$ and $v_{m}$ are the travel distance $(\mathrm{km})$ and speed $(\mathrm{km} / \mathrm{h})$ of the first mode of travel in the process of arriving at the leasing point from the starting point, respectively. $l_{2}$ is the distance from the lease point to the return point $(\mathrm{km}) ; v_{2}$ is the running speed of the rental car $(\mathrm{km} / \mathrm{h}) ; l_{n}$ and $v_{n}$ are the travel distance $(\mathrm{km})$ and speed $(\mathrm{km} / \mathrm{h})$ of the first mode of travel in the process of arriving at the destination from the return point, respectively; $y_{r k}$ is the construction cost of the $\mathrm{k}$ type (including land use cost, construction cost, maintenance cost, etc.) (ten thousand yuan) for the lease point or return point, where $r$ is the lease point or the return point. 
On the basis of obtaining the weights of each path, the total path weights are calculated [13]. The total route weight is closely related to the number of car users. Set the number of pedestrians arriving at the destination from the starting point as $M$, and the share rate of rental car is $X$. Among them, the weights of total travel time can be expressed by the sum of travel time of all travelers from the starting point to the destination, and the construction cost can be expressed by the construction cost of single service person, that is, the ratio of total construction cost to the number of service persons. The calculation equation can be expressed as follows:

Since there are many ways of arriving at the lease point or from the return point to the destination, different people will choose different modes of travel, which can be divided

into two situations. The first case is that the distance between the starting point and the leasing point or the change point and the destination is relatively close, and can be reached directly by walking without intermediate transfer. The second situation is that some travelers can arrive by sharing the transit modes of bicycle, bus, rail transit and taxi(when the transit conditions are satisfied). According to the above two cases, the weights of total travel time and construction cost are calculated as:

$$
\left\{\begin{array}{l}
Z_{1}=\sum_{i=1}^{M X} z_{1 i} \\
Z_{2}=\frac{z_{2}}{M X}
\end{array}\right.
$$

In the (6): $f_{1}$ and $f_{2}$ are the share rates of pedestrian mode in the process of arriving at the leasing point from the starting point and arriving at the destination from the return point, respectively; $f_{i}$ is the sharing rate of the $i$ type of conversion multiplication method in the process of reaching the rental point from the starting point; $f_{i}$ is the sharing rate of the $j$ type of conversion multiplication method in the process of returning the vehicle to the destination; $l_{1}$ is the path length of the starting point and the rental point $(\mathrm{km}) ; 1_{11}$, $1_{12}, 1_{13}$ are respectively the path length $(\mathrm{km})$ of starting point and intermediate transfer multiplier, intermediate transfer multiplier, intermediate transfer multiplier and leasing point; $l_{2}$ is the path length $(\mathrm{km})$ of the lease point and the return point; $l_{3}$ is the path length of return point and destination $(\mathrm{km}) ; l_{31}, l_{32}, l_{33}$ are respectively the path lengths $(\mathrm{km})$ between the return point and the intermediate transfer point, the intermediate transfer point and the destination; $v_{1}, v_{2}$ are running speeds of walking and renting cars respectively $(\mathrm{km} / \mathrm{h}) ; v_{i}$ uses the speed of running $i$ mode $(\mathrm{km} / \mathrm{h})$ as the starting point to reach the leasing point; $v_{i}$ is the running speed $(\mathrm{km} / \mathrm{h})$ of the $j$ type of travel mode when the returning point arrives at the destination.

\section{MODEL SOLUTION}

The layout of time-sharing leasing automobile network is determined by two objectives. Under a single objective, there will inevitably be the shortest paths $L_{1}^{0}$ and $L_{2}^{0}$ for a single objective, and the corresponding target weights are $\min Z_{1}$ and $\min Z_{2}$ respectively. Then the value is the ideal point for each objective. The target weights of $L_{i}$ set on the path are $Z_{1 i}$ and $Z_{2 i}$, for each target, there will inevitably be the path with the smallest target value and the path with the largest target value. Therefore, the target weight of each target range is $Z_{1}=\left[\min Z_{1}, \max Z_{1}\right]$ and $Z_{2}=\left[\min Z_{2}, \max \right.$ $\left.Z_{2}\right]$.

The target weight is $\left(Z_{1 i}, Z_{2 i}\right)$ on the $i$ path $L_{i}$. Because the dimension of travel time weight is different from that of construction cost weight, it is necessary to normalize the target value. The calculation equation of the target value is as follows:

$$
\left\{\begin{array}{l}
Z_{1 i}^{\prime}=\frac{Z_{1 i}-\min Z_{1}}{\max Z_{1}-\min Z_{1}} \\
Z_{2 i}^{\prime}=\frac{Z_{2 i}-\min Z_{2}}{\max Z_{2}-\min Z_{2}}
\end{array}\right.
$$

According to the normalized target weight and the weighted Euclidean distance algorithm, the distance $D_{i}$ between the target weight and the ideal point on the path $i$ can be obtained. The equation is as follows:

$$
D_{i}=\sqrt{w_{1} \times\left(Z_{1 i}^{\prime}-\min Z_{1}^{\prime}\right)^{2}+w_{2} \times\left(Z_{2 i}^{\prime}-\min Z_{2}^{\prime}\right)^{2}}
$$

In the (8): $w_{1}$ is the weight of travel time target; $w_{2}$ is the weight of the construction cost target, where $w_{1}$ and $w_{2}$ can be selected according to the actual situation of the scope of study; is the travel time weight of the ideal point after normalization; is the weight of the construction cost of the 
Combined with the above calculation method, the shortest path problem with two objectives can be converted into a single objective function. By calculating, the minimum value min $D_{i}$ is the shortest path from the starting point to the destination, and the leasing point through which the optimal network location of time-sharing leasing car can be obtained.

According to the double target shortest path model established above, combined with the Dijkstra basic algorithm [14, 15], based on the $K$ - shortest path algorithm, the solution method of the model is designed. The flow chart is shown in Figure 1.

$$
D_{i}=\sqrt{w_{1} \times Z_{1 i}^{\prime 2}+w_{2} \times Z_{2 i}^{\prime 2}}
$$

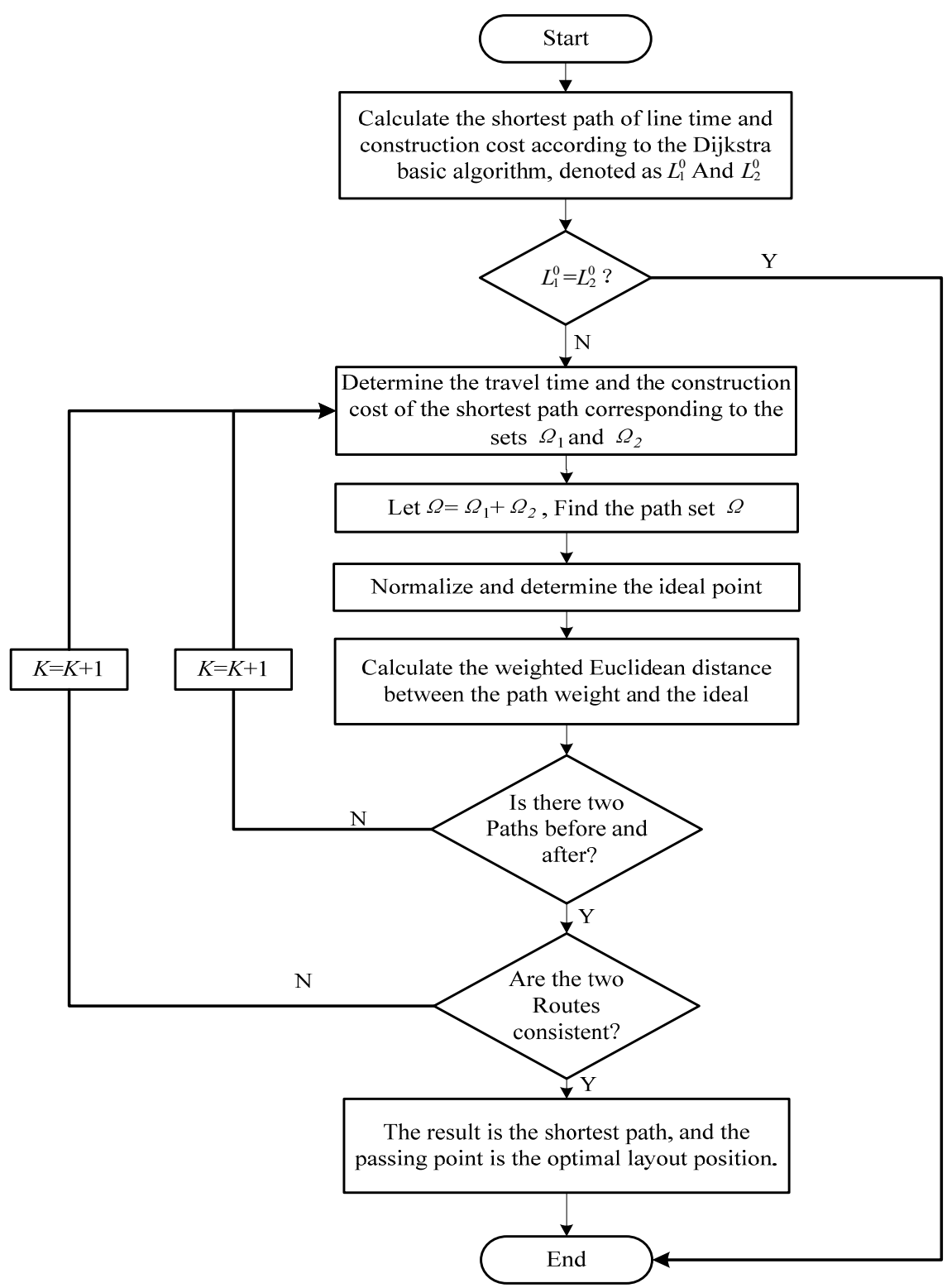

FIGURE I. FLOWCHART OF ALGORITHM 
and construction cost weight coefficient, this paper assumes that the weight of travel time and construction cost are each 0.50 . On the one hand, the determination of the weight of these two target items is itself a complicated game process, taking the same value can simplify the example; On the other hand, this paper argues that travel time and construction cost are equally important.

According to the survey, the total number of pedestrians per day in starting point $O$ is 2849 , of which $8.60 \%$ are rental vehicles. The weights of travel time and construction cost are shown in Tables 1-3.

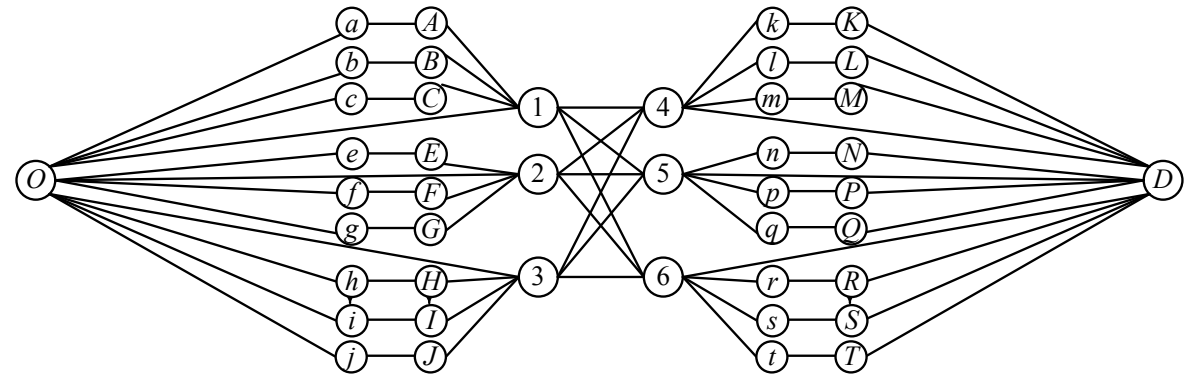

FIGURE II. THE PRELIMINARY LAYOUT OF TIME-SHARING LEASING AUTOMOBILE NETWORK

TABLE I. THE CALCULATION TABLE OF TARGET VALUE

\begin{tabular}{|c|c|c|c|c|c|c|c|c|}
\hline Node & $\begin{array}{c}\text { Travel } \\
\text { time(h) }\end{array}$ & $\begin{array}{c}\text { Construction } \\
\text { cost(10,000 } \\
\text { RMB) }\end{array}$ & Node & $\begin{array}{c}\text { Travel } \\
\text { time(h) }\end{array}$ & $\begin{array}{c}\text { Construction } \\
\text { cost(10,000 } \\
\text { RMB) }\end{array}$ & Node & $\begin{array}{c}\text { Travel } \\
\text { time(h) }\end{array}$ & $\begin{array}{c}\text { Construction } \\
\text { cost(10,000 } \\
\text { RMB) }\end{array}$ \\
\hline$(O, 1)$ & 0.55 & 0.32 & $(C, 1)$ & 0.10 & 0.32 & $(5, q)$ & 0.16 & 0 \\
\hline$(O, a)$ & 0.13 & 0 & $(E, 2)$ & 0.32 & 0.27 & $(6, D)$ & 0.73 & 0 \\
\hline$(O, b)$ & 0.16 & 0 & $(F, 2)$ & 0.37 & 0.27 & $(6, r)$ & 0.21 & 0 \\
\hline$(O, c)$ & 0.12 & 0 & $(G, 2)$ & 0.12 & 0.27 & $(6, s)$ & 0.34 & 0 \\
\hline$(O, 2)$ & 0.62 & 0.27 & $(H, 3)$ & 0.32 & 0.18 & $(6, t)$ & 0.12 & 0 \\
\hline$(O, e)$ & 0.18 & 0 & $(I, 3)$ & 0.29 & 0.18 & $(k, K)$ & 0.48 & 0 \\
\hline$(O, f)$ & 0.23 & 0 & $(J, 3)$ & 0.14 & 0.18 & $(l, L)$ & 0.24 & 0 \\
\hline$(O, g)$ & 0.16 & 0 & $(1,4)$ & 1.05 & 0.36 & $(m, M)$ & 0.21 & 0 \\
\hline$(O, 3)$ & 0.77 & 0.18 & $(1,5)$ & 1.13 & 0.21 & $(n, N)$ & 0.57 & 0 \\
\hline$(O, h)$ & 0.14 & 0 & $(1,6)$ & 1.28 & 0.25 & $(p, P)$ & 0.34 & 0 \\
\hline$(O, i)$ & 0.28 & 0 & $(2,4)$ & 0.98 & 0.36 & $(q, Q)$ & 0.18 & 0 \\
\hline$(O, j)$ & 0.11 & 0 & $(2,5)$ & 1.16 & 0.21 & $(r, R)$ & 0.42 & 0 \\
\hline$(a, A)$ & 0.35 & 0 & $(2,6)$ & 1.68 & 0.25 & $(s, S)$ & 0.28 & 0 \\
\hline$(b, B)$ & 0.22 & 0 & $(3,4)$ & 1.26 & 0.36 & $(t, T)$ & 0.17 & 0 \\
\hline$(c, C)$ & 0.18 & 0 & $(3,5)$ & 1.37 & 0.21 & $(K, D)$ & 0.24 & 0 \\
\hline$(e, E)$ & 0.41 & 0 & $(3,6)$ & 1.54 & 0.25 & $(L, D)$ & 0.38 & 0 \\
\hline$(f, F)$ & 0.16 & 0 & $(4, D)$ & 0.67 & 0 & $(M, D)$ & 0.11 & 0 \\
\hline$(g, G)$ & 0.13 & 0 & $(4, k)$ & 0.23 & 0 & $(N, D)$ & 0.26 & 0 \\
\hline$(h, H)$ & 0.28 & 0 & $(4, l)$ & 0.34 & 0 & $(P, D)$ & 0.41 & 0 \\
\hline$(i, I)$ & 0.18 & 0 & $(4, m)$ & 0.10 & 0 & $(Q, D)$ & 0.16 & 0 \\
\hline$(j, J)$ & 0.17 & 0 & $(5, D)$ & 0.72 & 0 & $(R, D)$ & 0.22 & 0 \\
\hline$(\mathrm{A}, 1)$ & 0.28 & 0.32 & $(5, n)$ & 0.27 & 0 & $(S, D)$ & 0.29 & 0 \\
\hline$(B, 1)$ & 0.37 & 0.32 & $(5, p)$ & 0.33 & 0 & $(T, D)$ & 0.37 & 0 \\
\hline
\end{tabular}

TABLE II. THE STATISTICS TABLE OF TRAVEL TIMES OF DIFFERENT TRANSFER MODE

\begin{tabular}{ccccccccc}
\hline \multirow{2}{*}{ Node } & \multicolumn{2}{c}{ Walk } & \multicolumn{2}{c}{ Bus transfer } & \multicolumn{2}{c}{ Rail Transit Transfer } & \multicolumn{2}{c}{ Taxi transfer } \\
\cline { 2 - 8 } & $\begin{array}{r}\text { Distributing } \\
\text { rat }\end{array}$ & $\begin{array}{c}\text { Travel } \\
\text { times }\end{array}$ & $\begin{array}{c}\text { Distributing } \\
\text { rat }\end{array}$ & $\begin{array}{c}\text { Travel } \\
\text { times }\end{array}$ & $\begin{array}{c}\text { Distributing } \\
\text { rat }\end{array}$ & $\begin{array}{c}\text { Travel } \\
\text { time }\end{array}$ & $\begin{array}{c}\text { Distributing } \\
\text { rat }\end{array}$ & $\begin{array}{c}\text { Travel } \\
\text { times }\end{array}$ \\
\hline$(O, 1)$ & $61.61 \%$ & 151 & $11.40 \%$ & 28 & $19.21 \%$ & 47 & $7.82 \%$ & 19 \\
$(O, 2)$ & $45.73 \%$ & 112 & $18.41 \%$ & 45 & $22.90 \%$ & 56 & $13.10 \%$ & 32 \\
$(O, 3)$ & $33.92 \%$ & 83 & $24.11 \%$ & 59 & $31.02 \%$ & 76 & $11.01 \%$ & 27 \\
$(4, D)$ & $56.71 \%$ & 139 & $16.72 \%$ & 41 & $17.60 \%$ & 43 & $9.03 \%$ & 22 \\
$(5, D)$ & $40.01 \%$ & 98 & $20.80 \%$ & 51 & $24.11 \%$ & 59 & $15.11 \%$ & 37 \\
$(6, D)$ & $37.62 \%$ & 92 & $22.91 \%$ & 56 & $27.81 \%$ & 68 & $11.82 \%$ & 29 \\
\hline
\end{tabular}


TABLE III. THE TABLE OF WEIGHTING

\begin{tabular}{lllllllll}
\hline Node & $\begin{array}{c}\text { Travel } \\
\text { time(h) }\end{array}$ & $\begin{array}{c}\text { Construction } \\
\text { cost(10,000 } \\
\text { RMB) }\end{array}$ & Node & $\begin{array}{c}\text { Travel } \\
\text { time(h) }\end{array}$ & $\begin{array}{c}\text { Construction } \\
\text { cost(10,000 } \\
\text { RMB) }\end{array}$ & Node & $\begin{array}{c}\text { Travel } \\
\text { time(h) }\end{array}$ & $\begin{array}{c}\text { Construction } \\
\text { cost(10,000 } \\
\text { RMB) }\end{array}$ \\
\hline$(O, 1)$ & 147.18 & 0.32 & $(1,6)$ & 313.60 & 0.25 & $(3,5)$ & 335.65 & 0.21 \\
$(O, 2)$ & 166.07 & 0.27 & $(2,4)$ & 240.10 & 0.36 & $(3,6)$ & 377.30 & 0.25 \\
$(O, 3)$ & 175.91 & 0.18 & $(2,5)$ & 284.20 & 0.21 & $(4, D)$ & 183.99 & 0 \\
$(1,4)$ & 257.25 & 0.36 & $(2,6)$ & 411.60 & 0.25 & $(5, D)$ & 213.28 & 0 \\
$(1,5)$ & 276.85 & 0.21 & $(3,4)$ & 308.70 & 0.36 & $(6, D)$ & 195.78 & 0 \\
\hline
\end{tabular}

According to the above calculation of the target weight, under the shortest target of the travel time, using the Dijkstra algorithm, the shortest path can be obtained as: $O$ $\rightarrow 1 \rightarrow 4 \rightarrow D, 0.68$ corresponding to the minimum travel time value of 588.42, the construction cost weight at this time is 0.68 . Under the requirement of minimum construction cost, the shortest path is $O \rightarrow 3 \rightarrow 5 \rightarrow D$, the corresponding minimum construction cost weight is 0.39 , and the travel time weight is 724.84 . Because the paths are different under different targets, it is necessary to select the optimal path by synthesizing various indicators. According to the calculation of the weights of the shortest path under each target, the ideal point is $(588.42,0.37)$.

Let $k=2$, the shortest path is $O \rightarrow 2 \rightarrow 5 \rightarrow D$, the corresponding travel time weight is 590.16 and the construction cost weight is 0.48. Under the minimum construction cost target requirements, the shortest path $O \rightarrow 3 \rightarrow 6 \rightarrow D$, the corresponding construction cost weight is 0.43 and the time weight is 748.99. From this we can get that the set of $\Omega$ is $\Omega=\{O 14 D, O 35 D, O 25 D, O 36 D\}$, Range of travel time and construction cost weight are $Z_{l}=[588.42$, 758.99] and $Z_{1}=[0.39,0.68]$.

The results are normalized according to (7). Taking $O \rightarrow 2 \rightarrow 5 \rightarrow D$ as an example, the calculation results are as follows:

$$
\begin{gathered}
Z_{11}^{\prime}=\frac{Z_{11}-\min Z_{1}}{\max Z_{1}-\min Z_{1}}=\frac{590.16-588.42}{748.99-588.42}=0.011 \\
Z_{12}^{\prime}=\frac{Z_{21}-\min Z_{2}}{\max Z_{2}-\min Z_{2}}=\frac{0.48-0.39}{0.68-0.39}=0.310
\end{gathered}
$$

According to the above calculation method, the weights of the paths in $\Omega$ can be obtained separately, and the results are shown in Table 4.

TABLE IV. THE CALCULATION TABLE OF $\Omega$ PATH WEIGHT NORMALIZATION

\begin{tabular}{lllll}
\hline & O14D & O35D & O25D & O36D \\
\hline Travel time(h) & 0 & 0.850 & 0.011 & 1 \\
Construction cost & 1 & 0 & 0.310 & 0.138
\end{tabular}

Combining Table 4 and (10), the weighted Euclidean distance between the line time weight and the construction cost weight and the ideal point is calculated. Taking $O \rightarrow 2 \rightarrow 5 \rightarrow D$ as an example, the calculation results are as follows:

$$
D_{1}=\sqrt{0.5 \times 0.011^{2}+0.5 \times 0.310^{2}}=0.219
$$

Similarly, according to (10), the weighted Euclidean distance between the weights of each path and the ideal point can be obtained. The results are shown in Table 5 .

\section{TABLE V. THE WEIGHTED EUCLIDEAN DISTANCE BETWEEN PATH WEIGHT AND IDEAL POINT}

\begin{tabular}{ccccc}
\hline Path & O14D & O35D & O25D & O36D \\
\hline$D i$ & 0.707 & 0.601 & 0.219 & 0.714 \\
\hline
\end{tabular}

According to the calculation results in Table 5, the weighted Euclidean minimum distance between the path weight and the ideal point is 0.219 , and the corresponding path is $O \rightarrow 2 \rightarrow 5 \rightarrow D$.

Let $k=3$, continue the above calculation steps, the shortest path is still $O \rightarrow 2 \rightarrow 5 \rightarrow D$. Therefore, the shortest path with $O \rightarrow 2 \rightarrow 5 \rightarrow D$ is obtained under the condition of double-objective constraint, and the optimal location of time-sharing rental car network are 2 and 5.

\section{CONCLUSION}

Based on the analysis of the factors affecting the layout of time-sharing rental car network, this paper chooses the travel time and construction cost as the objective, and constructs a two-objective shortest path model. The model first considers different travel modes such as walking, shared bicycle transit, bus transit, rail transit, taxi transit, etc from the starting point to the rental point or from the rental point to the destination, and the travel time for different transit modes are calculated. Secondly, by introducing the share rate of time-sharing leasing automobile, and combining with the number of users of time-sharing leasing automobile, the weights of time and construction cost are calculated. Thirdly, the weights of travel time and construction cost are normalized, and the minimum distance between the objective value of the path and the ideal point is obtained by calculating the weighted Euclidean distance, that is, the optimal path. The location of the time-sharing rental car network on the path is the optimal location. Finally, the feasibility of this method is verified by an examples. However, in practice, due to the uncertainty of 
travel time and the limitation of land scale, the application of the model has some limitations. In the follow-up study, these factors should be analyzed more deeply to improve the applicability of the model.

\section{REFERENCES}

[1] Robyn D., Sophia M., and Jennifer L. K. Sharing as sociomaterial practice: Car sharing and the material reconstitution of automobility. Geoforum, 2018, 88, 10-16.

[2] Joshua P., Laurens R., and Jan van D., Wolfgang K. Preferences for car sharing services: Effects of instrumental attributes and psychological ownership. Journal of Environmental Psychology, 2017, 53, 101-130.

[3] Liu Y. Q., Zhang L., and Li S. X., Innovative Research on Business Model of Electric Car Sharing in China Based on City Level. Scientific Decision-Making, 2017, 11, 29-53.

[4] Zhang G. W. Time-sharing Lease and Wisdom Travel. Journal of Transportation Systems Engineering and Information Technology, 2016, 16(4), 1-10.

[5] Gonçalo Correia, and António Antunes. Optimization approach to depot location and trip selection in one-way car sharing systems. Transportation Research Part E: Logistics and Transportation Review, 2012, 48(1), 233-247.

[6] Cepolina, E.M., and Farina, A New Shared Vehicle System for Urban Areas. Transportation Research Part C: Emerging Technologies, 2012, 21(1), 230-243.

[7] Li M. Time-sharing Rentals: The Development of Car Rental. Shanghai Auto, 2015, 3(3), 51-56.

[8] Zhang C. L. Improve the electric car time-sharing lease mode. China Development Observation, 2014, 11, 67-67.

[9] Ni A. N., Juan Z. C., and Gao L. J. An Overview of Research on Parallel Shortest Path Algorithmin Transportation Network. Journal of Highway and Transportation Research and Development, 2006, 23(12), 128-131.

[10] Han S., and Liu X. W. Fuzzy Optimal Solutions for Multiobjective Shortest Path Problems in the Logistics Transportation Network. Operation Research and Management Science, 2014, 23(5), 55-61.

[11] Sun X. J. Mathematical Model and Algorithm for a Bi-objective Fuzzy Shortest Path Problem. Journal of Chinese Computer Systems, 2015, 36(6), 1389-1392.

[12] Pangilinan J. M. A., and Janssen G. Evolutionary algorithms for the multiobjective shortest path problem. International Journal of Applied Science, 2007, 4(1), 205-210.

[13] Machuca E., Mandow L., and Pérezdelacruz J. L., A comparison of heuristic best-first algorithms for bicriterion shortest path problems. European Journal of Operational Research, 2012, 217(1), 44-53.

[14] Feng S. M., Wu H. Y., and Wang D. X. Study of Multi-objective Shortest Path Algorithm Based on Ideal Point Solution. Journal of Highway and Transportation Research and Development, 2016, 33(3), 97-101.

[15] Liu J. M., Ma S. F., and Ma S. Q. Computation method of the dynamic shortest path based on improved-Dijkstra algorithm. Systems Engineering-Theory \& Practice, 2011, 31(6), 1153-1157 